\title{
Prevalence of rotaviral infection in diarrheic neonatal calves in Mosul city, Iraq
}

\author{
I. A. Al-Robaiee and M. I. Al- Farwachi
}

Department of Internal and Preventive Medicine, College of Veterinary Medicine ,Mosul University, Mosul, I raq

Corresponding author: M. I. Al- Farwachi, email: maabalfrwche@yahoo.com

Received: 12-02-2013, Revised: 27-03-2013, Accepted: 29-03-2013, Published online: 27-05-2013

\section{How to cite this article:}

Al-Robaiee IA and Al-Farwachi MI (2013) Prevalence of rotaviral infection in diarrheic neonatal calves in Mosul city, I raq, Vet World 6(8): 538-540, doi: 10.5455/vetworld.2013.538-540

\begin{abstract}
Aim: The objective of the current study was to identify the prevalence of rotaviral infection in neonatal calves in Mosul city, Iraq.

Materials and Methods: From November 2010 to March 2011 a total 220 faecal samples were collected from both diarrheic $(\mathrm{n}=110)$ and non- diarrheic $(\mathrm{n}=110)$ neonatal calves, aged between 1-30 days from different part of Mosul city, Iraq. All faecal samples were analysed by capture direct ELISA kit.
\end{abstract}

Results: Rotaviral infection was found in $\mathrm{n}=17(15.5 \%)$ of 110 diarrheic calves and only 5 faecal samples $(4.5 \%)$ from 110 non-diarrheic animals.The prevalence of infection peaked in animals at $8-15$ days of age.

Conclusion: The data provides evidence for the role of rotavirus as a reason of neonatal calf diarrhoea in Mosul city, Iraq.

Keywords: calf, diarrhoea, prevalence, rotavirus

\section{Introduction}

Diarrhea is one of the chief causes of calf mortality, morbidity and economic losses in the cattle industry [1,2]. It is known that calves are affected by diarrhoea more at an early stage of the lactation period $[3,4]$. It is a complex multifactorial condition involving animal, environmental, nutritional and infectious agents [5-8]. Bovine rotavirus is the essential cause of neonatal calf diarrhea. In Iraq rotavirus was detected in faecal samples of calves in Baghdad by using agar gel precipitation test [9] and the virus was isolated from the diarrheic calves [10], Therefore the current study was conducted to throw light on the prevalence of rotavirus among neonatal diarrheic calves and to evaluate the currently used diagnostic tests.

\section{Material and Methods}

Animals: During the period from November 2010 to March 2011, a total 220 faecal samples were collected from local neonatal calves (1-30 days old) including, 110 calves suffering from diarrhoea that were randomly selected from field cases in the Mosul city, Iraq, which is about $400 \mathrm{~km}$ (250 miles) north-west of Baghdad (Figure-1).

The climate of the Mosul city is hot, dry at summer and cool rainy at winter. Other samples 110 samples were collected from non diarrheic (clinically healthy) animals of similar description from the same locality. Fecal samples were stored at $-20^{\circ} \mathrm{C}$ until further processing.

This article is an open access article licensed under the terms of the Creative Commons Attribution License (http://creativecommons org/licenses/by/2.0) which permits unrestricted use, distribution and reproduction in any medium, provided the work is properly cited.
Screening by ELISA: ELISA was performed to detect rotavirus antigen in the fecal samples as described by the kit manufacturer (Rotavirus ELISA kit, Bio-X Diagnostics, Belgium). The net optical density of each sample was calculated by subtracting the reading for each sample well from corresponding negative control. Net optical density (O.D) = O.D of specific binding O.D of non- specific binding

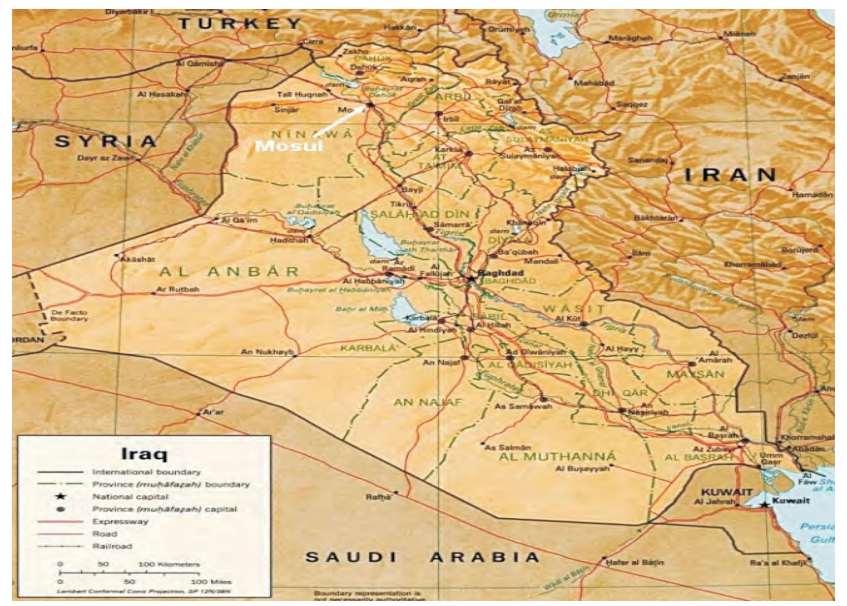

Figure-1. Map of Iraq, indicates the Mosul city

Any sample that yielded a difference of 0.15 or greater in optical density was considered positive.

\section{Results}

Results indicated that 17 out of 110 from diarrheic calves $(15.5 \%)$ and five out of 110 for non-diarrheic animals $(4.5 \%)$ were found to be positive for rotaviral infection (Table-1). Distribution of antigen positive samples with direct ELISA corresponding to ages were shown in (Figure-2). 
Table-1. Prevalence of bovine rotavirus in diarrheic neonatal calves in Mosul city

\begin{tabular}{lcc}
\hline Animal category & No. of positive animals & Percentage \\
\hline $\begin{array}{l}\text { Diarrheic animal } \\
(n=110)\end{array}$ & 17 & 15.5 \\
$\begin{array}{l}\text { Clinically healthy animal } \\
(n=110)\end{array}$ & 5 & 4.5 \\
Total $(n=220)$ & 10.0 & 22 \\
\hline
\end{tabular}

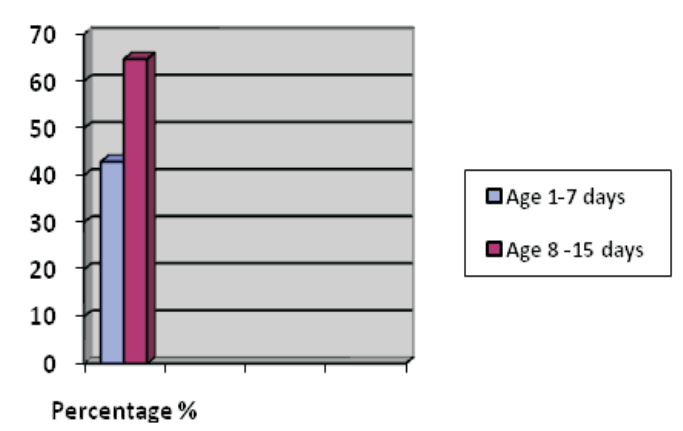

Figure-2. Distribution of antigen positive samples of diarrheic animals age-wise

\section{Discussion}

In this study rotaviral infection was found in 15.5 $\%$ of diarrheic calves. Rotavirus infection is considered as the basic cause of diarrhea and enteritis in calves $[11,12]$. The prevalence of rotaviral infection in calves varies depending on the country and region under study $[3,13]$. In previous works there is no published information on the epidemiology of rotavirus infection in neonatal calves in Mosul city, Iraq. Prevalence of rotavirus as the causative agent of neonatal calf diarrhoea have been reported from many countries including $16.8 \%$ in Southern Italy [11], 19.4\% in Brazil [13], $26.4 \%$ in Quebec [14] and 8.5\% in Turkey [15]. The discrepancy between our results and those of other studies $[11,13,14,15]$ could be attributed to geographical differences and differences in timing of sample collection.

In the present study, rotavirus antigen was detected in only five faecal samples $(4.5 \%)$ of 110 nondiarrheic animals. The occurrence and distribution of the rotavirus in non diarrheic and clinically normal calves have been previously studied. Rotaviral antigen was found in 3 of 136 healthy calf faeces [16], while rotavirus antigen was detected in only two $(4.08 \%)$ of the 49 healthy calves [17]. Also, natural subclinical infections are common in calves in the second week of life [3]. Diarrhea or excretion of abnormal faeces was associated with rotavirus infection in $58 \%$ of infected calves, while in the remaining $42 \%$, infection was subclinical [3].

In our study diagnosis of rotavirus infection in neonatal calves was based on the results of capture direct ELISA kit. Rotavirus destroys small intestinal enterocytes resulting in diarrhea which is accompanied by a profuse fecal shedding of virus $[3,18]$. In fact, such vast numbers of rotavirus particles occur in diarrheal faeces. Thus, it is possible to diagnose this infection by negative staining, electron microscopic examination of fecal specimens $[3,19]$.Till today a variety of methods are used to detect bovine rotavirual infection in faeces like electron microscopy [19], Latex agglutination test $[20,21]$, virus isolation in cell culture [20], ELISA and PCR [21,22].

ELISA is one of the essential methods in the determination of viral antigens. It is used widely in calves with diarrhea in faeces for determination of rotavirus $[15,17,18,19,21,23]$. ELISA had the advantage of being inexpensive for examination of many samples and has the probability of being much more sensitive $[15,18]$.

In our study, the highest rate of infection was recorded in the diarrheic calves in 8-15 days of age. Rotaviruses play a sizable role in the aetiology of neonatal calf diarrhoea and found in the faeces of diarrheic calves up to 3 rd week of life [3]. Calves are known to excrete the virus through faeces by the secondary infection which continues for 7-8 days and susceptible calves of 2-3 weeks age may get infected $[3,24]$.

\section{Conclusion}

The study suggests the role of rotavirus as a serious cause of neonatal calf diarrhea in Mosul city, Iraq. Further studies are needed to understand the dynamics of rotavirus transmission, cycle, and to identify alternative management practices to minimize the risk to animals.

\section{Acknowledgements}

The authors are grateful to authorities of College of Veterinary Medicine, Mosul University, Mosul, Iraq for providing fund and facilities for this study.

\section{Authors' contribution}

All authors contributed equally. All authors read and approved the final manuscript.

\section{Competing interests}

The authors declare that they have no competing interests.

\section{References}

1. Leslie, K. E. and Todd, C. G. (2007) Keeping your calves healthy. WCDS Adv. Dairy Technol.,19:285-300.

2. Razzaque, M. A., AL-Mutawa, T. and Mohammed, S. A. (2010) Diarrhea in pre- weaned calves :Relative risk rates for morbidity and mortality in 13 commercial farm of hot airdzone. Am. J.Anim. and Vet. Sci., 5(3):215-220.

3. Radostits, O. M., Gay, C. C., Hinchcliff, K. W. and Constable, P. D. (2007) Veterinary. Medicine. A text book on disease of cattle, sheep, pigs and horse $10^{\text {th }}$ Ed., Saunders Elsevier, Edinburgh, pp. 74-94,103,262-263, $206,847$.

4. Gulliksen, S. M., Lie, K. I., Solverod, L. and Oteras, O. (2008) Risk factors associated with colostrum quality in Norwegian dairy cows. J. Dairy Sci., 91:704 -712.

5. Sivula, N. J., Ames, T. R., Marsh, W. E. and Werdin, R. E. 
(1996) Descriptive epidemiology of morbidity and mortality in Minnesota dairy heifer calves. Prev. Vet. Med., 27: 155-171.

6. Svensson, C. K., Lundborg, U., Emanuelson, U. and Olsson, S. (2003) Morbidity in Swedish dairy calves from birth to 90 days of age and individual calf level risk factors for infectious diseases. Prev. Vet. Med. 58:179-197.

7. Svensson, C., Hultgren, J. and Oltenacu, P. A. (2006) Morbidity in 3-7-month-old dairy calves in southwestern Sweden, and risk factors for diarrhoea and respiratory disease. Prev. Vet. Med. 74:162-179.

8. Gulliksen, S. M., Jor, E., Lei, K. I., Hamnes, L. S., Loken, T., Akerstedt, J. and Osterans, O. (2009) Enteropathogens and risk factor for diarrhea in Norwegian calves. J. Dairy Sci., 92:5057-5066.

9. Hasso, S. A. (1982) Investigation of Rota virus in neonatal cattle and buffalo calves. Thesis of M.Sc. in Veterinary medicine, College of Vet. Med. University of Baghdad.

10. Saeed, A. E. (1992) Isolation of rotavirus from diarrheic calves. Thesis of M.Sc. in Veterinary medicine, College of Vet. Medicine, Mosul University.

11. Pisanelli, G., Martella, V., Pagnini, U., Demartino, L., Lorusso, E., Iovane, G. and Buonavogalia, C. (2005) Distribution of G (VP7) and (VP4) genotypes in buffalo group A rotaviruses isolated in Southern Italy. Vet. Microbiol., 110:1-6.

12. Rathi, R., Kadian, S. K., Khurana, B., Grover, Y. P. and Gulati, B. R. (2007) Evaluation of immune response to bovine rotavirus following oral and intraperitonial inoculation in mice. Indian Journal of Experimental Biology,45:212-216.

13. Alfieri, A. A., Parazzi, M. E., Takiuchi, E., Medici, K. C. and Alfieri, A. F.(2006) Frequency of group A rotavirus in diarrheic calves in Brazilian cattle herd ,1998-2002.Tropical Animal Health and Production,38,521-526.

14. Hussein, A. H., Cornaglia, E., Saaber, M. S. and El-Azhary, (1995) Prevalence of serotype G6 and G10 group A rotaviruses in dairy calves in Quebec. Canadian Journal of Veterinary Research, 59: 235-237.
15. Duman, R. and Aycan, A. E. (2010) Prevalence of rotavirus infection in calves with diarrhea in Konya region. J. Anim. Vet. Adv., 9(1):136-138.

16. Myers, L. L., Firehammer, B. D., Border, M. M. and Hoop, D. S. (1984) Prevalence of enteric pathogens in the faeces of healthy beef calves. Am. J. Vet. Res., 45: 1544-1548.

17. Gumusova, S. O., Yazýcý, Z., Albayrak, H. and Meral, Y. (2007) Rotavirus and corona virus prevalence in healthy calves and calves with diarrhea. Medycyna Wet., 68 (1) :6264.

18. Badiei, K., Pourjafar, M. and Ghane, M. (2010) Fecal rotavirus antigen in diarrheic calves of high and average producing Holstein dairy cows. Global Veterinaria, 5(3): 175-197.

19. Ali, Y. H., Khalafalla, A. I., Gaffar, M. E., Peenz, I. and Steel, A. D. (2008) Detection and isolation of group A rotavirus from camel calves in Sudan. Vet. Arhiv. 78:477-485.

20. Al-yousif, Y., Anderson, J., Chard-Bergstrom, C., Bustamant, A., Muenzenberger, M., Austin, K. and Kapil, S. (2001) Evaluation of a latex agglutination kit (virogenrota test) for detection of bovine rotavirus in fecal samples. Clin. Diagn. Lab. Immunol. 8(3): 496-498.

21. Khafagi, M. H., Mahmoud, M. A. and Habashi, A. R. (2010) Prevalence of rotavirus infections in small ruminants. Global Veterinaria, 4(5): 539-543.

22. Dhama, K., Chauhan, R. S., Mahendran, M. and Malik, S. V. S. (2009) Rotavirus diarrhoea in bovine and other domestic animals. Vet. Res. Commun., 33:1-23.

23. Mayameei, A., Mohammadi, G., Yavari, S. A., Fishery, E. and Omidi, A. (2010) Evaluation of relationship between rotavirus and corona virus infection with calf diarrhea by capture ELISA. Comp. Clin. Pathol., 19:533-557.

24. Steele, A. D., Geyer, A. and Gerdes, G. H. (2004) Rotavirus infections. In: Coetzer JAW, Tustin RC (Eds), Infectious disease of livestock, Oxford university press, Southern Africa, 1256-1264. 